\title{
EZ Phone: Persuading Mobile Users to Conserve Energy
}

\author{
Abdullah Al Mahmud, \\ Omar Mubin \\ Dept. of Industrial Design, \\ Eindhoven University of Technology, \\ Eindhoven, \\ the Netherlands \\ \{a.al-mahmud, o.mubin\}@tue.nl
}

\author{
Suleman Shahid \\ Dept. of \\ Communication and \\ Information Sciences, \\ University of Tilburg, \\ the Netherlands \\ s.shahid@uvt.nl
}

\author{
Boris de Ruyter \\ Media Interaction, \\ Philips Research, \\ Eindhoven, the \\ Netherlands \\ boris.de.ruyter@ \\ philips.com
}

\begin{abstract}
Mobile persuasion is using a mobile device to motivate people to change their behavior in a positive way. Thus there is the potential in investigating how mobile technology could motivate people to change their behavior towards energy use in a home setting. In this paper we report a pilot study that was conducted to determine which of three visualization media (text, audio, multimedia) on a mobile device (EZ Phone: Energy Zaving Phone) can be the most effective in persuading users to conserve energy in a home setting. The design of the device was presented in the form of a video prototype. The study was carried out as a between subjects design with the type of medium the independent variable and persuasion was measured in the form of subjective perception. Our results show that text (SMS) is perceived to be the most persuading and Multimedia Message Service (MMS) the least persuading. We also present our thoughts on the implications to design and future development of our ongoing research on mobile persuasion.
\end{abstract}

\section{Categories and Subject Descriptors}

H.5.2 [User Interfaces]: User Interfaces - evaluation /methodology, user-centered design, prototyping.

\section{General Terms}

Measurement, Design, Experimentation, Human Factors

\section{Keywords}

Mobile persuasion, energy saving, scenarios

\section{INTRODUCTION}

Energy conservation is the practice of reducing the use of energy; which is a critical issue in today's developing world. Since there is a limited amount of nonrenewable (e.g. oil, gas, coal etc) energy sources on earth it is important to conserve the current supply of energy for future use and emphasis should be given to consume renewable energy sources (wind power, hydropower, solar). Due to the improper management of electrical appliances in our households, substantial energy is being wasted. Research results

C) The Author 2008.

Published by the British Computer Society show that energy consumption in households is increasing day by day and changes in human behavior are needed to save energy rather than just depending on technology. Persuasive technology has been deployed to motivate people to help them in behavioral change and human well-being is focused as the key applications of persuasion [7]. For instance, direct feedback on energy conservation at home can help in a positive behavioral change [5, 6]. Even computer games have been used to increase environmental awareness and to enhance energy usage patterns [2] and life-like social agents [1] can motivate people to save energy. Mobile phone nowadays is a strong and important platform to change human behavior. The use of mobile device is ubiquitous and almost everyone of us uses mobile phones as an integral part of their daily life regardless of if we are at home or at work. Moreover, our mobile devices are able to gather and report up-to-date and contingent information that is relevant to us, our goals and our context. Therefore mobile devices can help to motivate people more effectively than any other appliance that they use in their daily life both in and out of home.

It is foreseen that mobile phones will be the dominant channel for persuasion. B.J. Fogg $[3,4]$ mentioned that mobile platforms can motivate people to achieve their own personal goals and a mobile device helps to succeed like a magic wand. He also added that, 'mobile technology can layer information into our moment-bymoment lives in a way that changes our behavior'. We argue that the power of mobile persuasion can and will be used to enhance the quality of life in today's society by motivating humans to use energy efficiently.

Our goal is to design an interactive persuasive system (EZ Phone: Energy Zaving Phone) that can encourage energy conservation in a home setting by offering timely feedback, advice, praise, and incentives. The feedback should be given in such a way that users perceive it to be supportive rather than dominating or possessive (controlling). Hence, characteristics of the persuasive medium are important prior to employing it for motivational purposes. It is imperative to investigate the effect of a medium in mobile persuasion for energy saving purposes, i.e. which medium would result in being perceived as the most persuasive. In this study, we wished to examine which of the three media (SMS, MMS or Audio) a user finds as more persuading and productive of compliance with the advice given through that medium. Our initial design was represented in the form of a video prototype. The video scenarios used in our study were created by following the rules of mobile persuasion as mentioned in [4]. 


\section{EXPERIMENT}

\subsection{Participants}

In total we had 32 participants (20 male and 12 female) roughly divided equally over each condition (see Table 1). Their age ranged from 20 to 36 (Mean $=26.2$ ). The participants were recruited through email invitations. All participants had sufficient knowledge of the English language, which was the medium of instruction of the experiment.

\subsection{Design}

The experiment was conducted as a simple three condition between participants design. The type of the medium (Text, Audio, Video/MMS) was the main independent variable (see Table 1).

Table 1. Number of Participants: Medium type vs. gender

\begin{tabular}{|c|c|c|c|}
\cline { 3 - 4 } \multicolumn{1}{c|}{} & Male & Female \\
\hline \multirow{3}{*}{$\begin{array}{c}\text { Medium } \\
\text { Type }\end{array}$} & Text & 7 & 4 \\
\cline { 2 - 4 } & Audio & 5 & 4 \\
\cline { 2 - 4 } & Video & 8 & 4 \\
\hline
\end{tabular}

For the experiment, we used three different variants of the video (each portrayed a variant interaction technique with the mobile phone), which characterized our independent variable. We also wanted to explore gender effects, if any, and we investigated it as our second independent variable.

\subsubsection{Measurements}

In order to evaluate and measure the perceived persuasion of the EZ Phone by the participants, we used items from the scales (7point Likert) devised by Warner and Sugarman [6]. The items from the questionnaire were also embedded with some dummy items. 'Perceived Persuasion' was taken to be as the mean of the following four items: Ignorant - Knowledgeable, Irresponsible Responsible, Unintelligent - Intelligent, Unreliable/Untrustworthy - Reliable/Trustworthy. One study [1] used a similar metric from the questionnaire and achieved a Cronbach Alpha of 0.709 . Besides a quantitative question (one 7-point item - 'I will comply with the advice of such a phone'), a qualitative comment question was added to determine the compliance of the subjects ('Compliance') with the EZ Phone.

Further items (7 point Likert scales) investigated the perceived clarity of the scenario (to validate that the information provided by each medium was the same: 'Scenario Clarity') and the appreciation of the particular type of medium ('Medium Appreciation'). We also recorded qualitative remarks of the participants related to their user experience with the EZ Phone. Supplementary to the subjective opinion of the participants we also recorded demographic information, such as experience with mobile phones in general and experience with SMS, Voice SMS and MMS.

\subsection{Procedure}

The experiment was conducted either online or in a laboratory setting. In the second case, the facilitator welcomed the participant to the laboratory and left before the participant started the experiment. For both cases a set of instructions was outlined, which the subjects read carefully before starting the experiment. Moreover, for both cases the video was shown on the online YouTube interface [11]. Each participant was given a particular type of video to view (each video lasted for approximately 8 minutes), followed by the questionnaire.

\subsection{Apparatus and materials}

The videos were role-plays simulated by the researchers. The EZ Phone was a conceptualized via a mock up of a mobile phone. For all three videos the scenarios and storyline used were identical, however, the medium in which the persuasive information was presented was different.

Each video consisted of two scenes, each scene dealt with a different aspect related to energy conservation. The scenes were chosen as the typical daily home activities of a person. The storyline was built around a character ("Suleman") who owned the EZ Phone (see Figure 1a). The first scene portrayed the character leaving a television on standby mode and leaving the room. The second scene illustrated a similar situation, in which the character was shown to go to the kitchen and leaving the lights on when exiting. The persuasive information regarding energy consumption and conservation that was presented to the role actor in the video was modeled on the following three steps: reminding, warning and rewarding. A typical excerpt is shown below (reminding and warning: from the first scene):

Suleman, do you know the TV is still on and in standby mode?, It is consuming a lot of energy. Last month your electricity bill was the highest in the past 1 year.

In the video, the actor was shown to switch the TV off. The next

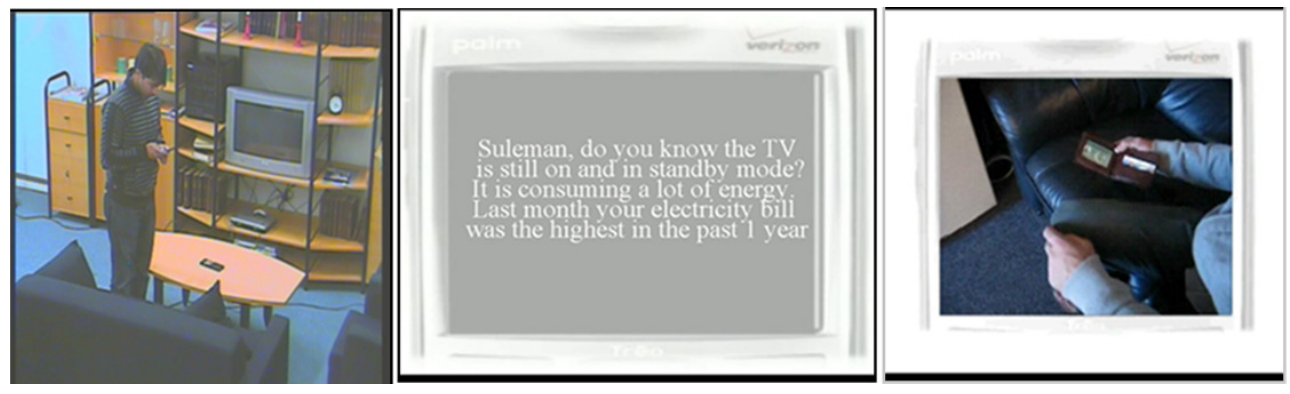

Figure 1. Snapshots from video scenario: a) reminding in mobile phone(left), b) SMS video (middle) and c) video snippet from MMS video (right) 
piece of information was (rewarding):

Good Suleman, remember that every unit of energy saved is useful for the environment, easy on your wallet and will help you in winning the energy competition of the most environmentally friendly citizen within your neighborhood.

\subsubsection{Video Design}

The scripts were reproduced across each of the three conditions. The base video was consistent for all three videos, with the only manipulation existing in information representation. For Video A (text medium) the persuasive information was presented in a snapshot of the phone as simple text (see Figure 1b). However for Video B (audio medium) the same text was simply presented as voice over. In this case the same mobile phone snapshot (see Figure 1b) was shown but it contained no text.

The design of Video C (Images, MMS and/or video medium) was rather more complicated. In order to ensure that there was no bias in Video $\mathrm{C}$ and that there was no explicit or extra information portrayed as compared to the earlier two videos we carried out a pre-pilot study. Users ( $\mathrm{N}=5$, not used for the main experiment) were presented with the text related to energy consumption and conservation (reminding, warning and rewarding) and were asked to reproduce the text in the form of a story board. A sample storyboard is shown (see Figure 2). Using the storyboard we designed a sub-video in MMS style using images, animations and video snippets. The information was purely visual and consisted of no audio and very limited text (see Figure 1c). In order to validate our findings we conducted a reciprocal pilot study. The MMS sub-video was presented to pilot users $(\mathrm{N}=4$, not used for the main experiment) and they were asked to reproduce it in the form of text. Using the findings from both sessions of our pilot experiment we modified our MMS sub-video slightly and came up with the final design of Video C.

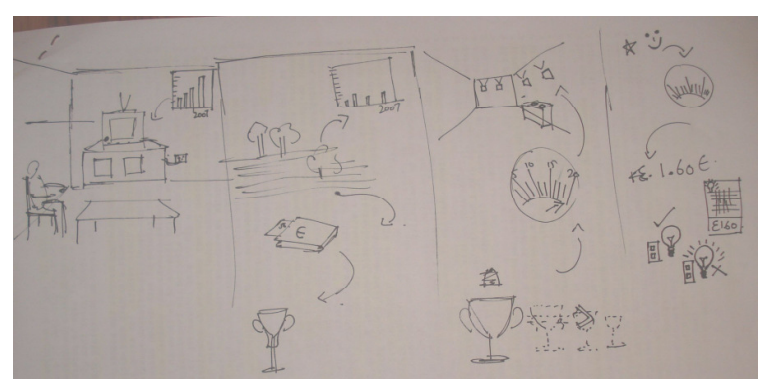

Figure 2. Storyboard sketch of the video scenario from a participant.

\section{RESULTS}

Before proceeding with evaluating the effect of the medium type on our dependent variables, we observed the trends from the demographic data. On a scale of 1 (low) to 5 (high) rating experience with mobile phones, the mean was 3.97 (minimum was 2 , rated by one participant only). Text messaging (SMS) was observed to be most often used interaction (out of SMS, MMS and Voice messaging), $81 \%$ used SMS several times or more in a week. SMS was also rated by a large number of participants as the most popular communication technique $(87 \%)$. Participants used their mobile device for numerous purposes: communication, alarm, calendar, watch, agenda organizer, etc. To analyze the main effects of medium type on our four dependent variables
(Perceived Persuasion, Compliance, Scenario Clarity, Medium Appreciation) we ran an Analysis of Variance (ANOVA). Caution must be taken while interpreting our results, as our sample size was low. We achieved a Cronbach Alpha of 0.82 across the four Perceived Persuasion items, which gave us sufficient reliability and confidence in this particular measurement. Medium Type had a significant effect on Perceived Persuasion $F(2,28)=3.65, \underline{p}=$ 0.039 . Text was perceived to be the most persuasive medium by participants (see Table 2). However, Medium Type did not have an effect on Compliance $F(2,28)=1.06, \underline{p}=0.36$ or on Medium Appreciation $\mathrm{F}(2,28)=1.33, \mathrm{p}=0.28$. Moreover, Medium Type did not have a significant influence on Scenario Clarity $\mathrm{F}(2,28)=$ $2.25, \mathrm{p}=0.12$, which lends creditability to our claim that all three video conditions provided information in an identical context and that there was no bias extending from any particular video type. As a precaution, we repeated the analysis by performing a non parametric test (Kruskal Wallis) and observed that Medium Type had an effect on Perceived Persuasion only $\chi^{2}(2,32)=6.20$, p $=0.045$. Gender did not have an effect on any of the dependent variables. Interesting to note, was that on average the most appreciated medium by females was Audio, and for males Text. There was no interaction effect between Medium Type and Gender.

Table 2. Likert Rating Means and Standard Deviations: Medium type vs. Perceived Persuasion, Compliance and Medium Appreciation

\begin{tabular}{|c|c|c|c|c|c|}
\hline & & & \multirow[b]{2}{*}{$\begin{array}{l}\text { Perceived } \\
\text { Persuasion }\end{array}$} & \multirow[b]{2}{*}{$\begin{array}{l}\text { Compli- } \\
\text { ance }\end{array}$} & \multirow[b]{2}{*}{$\begin{array}{l}\text { Medium } \\
\text { Appreci- } \\
\text { ation }\end{array}$} \\
\hline & & & & & \\
\hline \multirow{6}{*}{$\begin{array}{l}\text { Medium } \\
\text { Type }\end{array}$} & \multirow[b]{2}{*}{ Text } & Mean & 5.91 & 4.91 & 4.55 \\
\hline & & Std. Deviation & 0.85 & 1.76 & 1.57 \\
\hline & \multirow{2}{*}{ Audio } & Mean & 5.38 & 4.88 & 3.75 \\
\hline & & Std. Deviation & 0.91 & 1.25 & 1.67 \\
\hline & \multirow[b]{2}{*}{ Video } & Mean & 5.02 & 4.17 & 3.58 \\
\hline & & Std. Deviation & 0.63 & 0.94 & 1.24 \\
\hline
\end{tabular}

Correlations across the dependent variables (Perceived Persuasion, Compliance, Medium Appreciation) were all significant. The strongest correlation was observed between Medium Appreciation and Compliance $(\underline{r}=0.59, \mathrm{p}<0.01)$.

\section{DISCUSSION}

Our quantitative results indicate that Text could be the ideal medium when it comes to mobile persuasion. Firstly, participants rated Text interaction as the most preferable medium and secondly it was perceived as the most persuasive of the three. During the laboratory experiments and online surveys, we it was perceived as the most persuasive of the three. However we did not observe an effect in compliance. extracted several valuable comments from the participants. Nearly all subjects appreciated the motivation of the design of the EZ Phone and expressed an awareness towards energy conservation. One participant said, 'The idea of alerting the user to turn things off and not automatically doing it is a really good one'. Participants appreciated the idea of receiving reminders on their mobile phone, as they are mobile nearly all the time. Some participants suggested that appliances should be 
switched off automatically and/or remotely but the essence of our design was to persuade users by creating an energy awareness and hence changing their behavior.

Participants were of the opinion that the reminders should be simple, short and to the point. One participant who was from the audio condition commented that, 'I did not like the way it started talking to me. It can also show the same thing using some text or ask me how do I want to view this information'. Generally, users figured out that text is more pragmatic, saves time as video cannot be relayed at once. With MMS for example it would be difficult to deliver an urgent message concisely, even though MMS can provide a richer context.

Another participant said, 'I would prefer a shorter text message with more direct information. I'm not used to reading an entire paragraph on a mobile phone display.' Results reported in [8] comparing users' mobile media choices found that audio is suitable for situations where users are on the move and when users are sitting or standing static text or video is the preferred media choice as perceived by users. Hence given that the context of the design of the EZ Phone is a home setting, we would expect that text medium would be the most appropriate.

Another study [5] which examined medium effects on persuasion in person-to-person communication found that participants were more convincing in text chat condition. Similarly in the EZ Phone, even though interaction is system to person, participants perceived SMS as the most viable medium for persuasion. Our results also comply with the study mentioned in [4] in which SMS was used to promote the sexual health of young people. However we agree with Dean Eckles [4] that 'messages are not the core of persuasion as they don't exist in isolation'. Persuading text messages are most effective when presented as a part of ongoing interaction just as we also exhibited in our scenario.

Lastly we would like to point out that there are some limitations in our study. First of all, the application concept was shown as a video prototype in which participants did not interact with the real system, hence perceived persuasion is subjective in nature. However, we think that for early exploration to build such a system such kind of an investigation can direct to a logical path to build the envisioned system. Secondly, we did not manipulate the content of the message. Instead, we focused on the nature of the medium (text vs. audio vs. multimedia) but we did not focus on the actual semantics of the message and the semiotics of the communication could be a key factor in persuasion.

\section{CONCLUSIONS AND FUTURE WORK}

In summary, Text emerged as the most compelling medium for persuasion. However we believe that it also depends on the context in which one medium is more appropriate or suitable than the other. A combination of medium could also be perceived as more persuading in a context other than energy conservation. Since text reminders can be delivered at the most opportune moment users find them to be more persuading, provided they are in time. For the next step, we will build a functional prototype in which we would like to measure the influence of way the message is expressed for e.g., friendly, un-friendly, flattering, direct request etc.) and test the effect of mixed media on mobile persuasion in the form of a longitudinal study. Only then can we accurately claim that a particular medium has incurred any behavioral change. In sum we believe that the power of mobile persuasion in conjunction with appropriate media will help to change human behavior in order to maintain a sustainable society.

\section{ACKNOWLEDGMENTS}

We thank all the participants for taking part in this study.

\section{REFERENCES}

[1] Al Mahmud, A., Dadlani, P., Mubin, O., Shahid, C.S., Midden, C.J.H. (2007). iParrot : towards designing a persuasive agent for energy conservation. In Y.A.W. de Kort, W.A. IJsselsteijn (Eds.), Persuasive Technology: Second International Conference on Persuasive Technology, PERSUASIVE 2007, LNCS, Vol. 4744, pp. 64-67,. Berlin: Springer.

[2] Bang, M., Torstensson, C., Katzeff, C.: The PowerHouse: A persuasive computer game designed to raise awareness of domestic energy consumption. In: IJsselsteijn, W.A., de Kort, Y.A.W., Midden, C.J.H., Eggen, J.H., van den Hoven, E.A.W.H. (eds.),

[3] Fogg, B. J., Persuasive Technology: Using Computers to Change What We Think and Do. Morgan Kaufmann Publishers, San Francisco, CA, 2003.

[4] Fogg, B.J. and Eckles, D., 20 Perspectives of Future of Behavior Change, Stanford Captology Media, 2007

[5] Heim, J., Asting, T., Schliemann, T., Medium effects on persuasion, NordicCHI October 19-23, 2002, 259-263.

[6] McCalley, T., Kaiser, F., Midden, C.J.H., Keser, M., Teunissen, M., Persuasive appliances: Goal priming and behavioural response to product-integrated energy feedback. In: IJsselsteijn, W.A., de Kort, Y.A.W., Midden, C.J.H., Eggen, J.H., van den Hoven, E.A.W.H. (eds.), PERSUASIVE 2006. LNCS, 3962, New York, Springer Verlag (2006) 4549.

[7] McCalley, L. T., \& Midden, C. J. H., Energy conservation through product-integrated feedback: The roles of goalsetting and social orientation. Journal of Economic Psychology, 23, 5, 589-603(2002).

[8] Oksman, V., Noppari, E., Tammela, A., Mäkinen, M., Ollikainen, V., News in mobiles-comparing text, audion and video, VTT research notes, 2007

[9] Tschelig, M., and Reitberger, W., Persuasion as an ingradient of societal interface, Interactions, September+October, 2007

[10] Warner, R.M. and Sugarman D.B., Attributes of Personality Based on Physical Appearance,Speech, and Handwriting. Journal of Personality and Social Psychology, 1996. 50(4): p. 792-799.

[11] www.youtube.com 